\title{
Validation of an NLP Scale and its Relationship with Teacher Success in High Schools
}

\author{
Reza Pishghadam \\ Ferdowsi University of Mashhad, Iran \\ Email: pishghadam@um.ac.ir \\ Shaghayegh Shayesteh \\ Ferdowsi University of Mashhad, Iran \\ Email: shaghayegh.shayesteh@gmail.com \\ Mitra Shapoori \\ Ferdowsi University of Mashhad, Iran \\ Email: mitrashapoori@yahoo.com
}

\begin{abstract}
The major aims of this study were first to construct and validate a questionnaire of NeuroLinguistic Programming (NLP) and second to examine its relationship with teacher success in the context of Iran. To this end, a questionnaire was designed by picking up the most frequently-used indicators of NLP. To validate the questionnaire, Exploratory Factor Analysis was performed. Then, the authors sought to find out the relationship between NLP and English language teachers success at high schools. Results indicated that there is a significant association between NLP and teacher success. Finally, statistical results were discussed, and implications were provided in the context of English language teaching.
\end{abstract}

Index Terms - neuro-linguistic programming, language teaching, construct validity, factor analysis

\section{INTRODUCTION}

Effective teaching requires fostering good relationship with learners. Learners open their minds to the teacher who rules their hearts and souls. Learners generally express themselves in classes in which teachers know how to establish effective relationship with them. Teachers by building rapport and having effective communication with their students can facilitate the process of learning. Neuro-Linguistic Programming (NLP), as an important concept in humanistic psychology, deals with the art of communication and the study of the structure of subjective experience (Tosey, Mathison \& Michelli, 2005). In fact, NLP is a set of general communication techniques and strategies for building rapport, personal change, and learning.

As O' Connor (2001) defined "NLP studies brilliance and quality_ how outstanding individuals and organizations get their outstanding results" (p. 1). Furthermore, Kudliskis and Burden (2009) explained NLP as a modeling process in which people try to learn and gain the art of "communication excellence". Originally, NLP was a major theme exclusively in the fields of counseling and psychotherapy (Gumm, Walker \& Day, 1982; Sharply, 1984; Einspruch \& Forman, 1985; Tosey, Mathison \& Michelli, 2005); whereas, today this technique is being utilized by many other practitioners including: managers, consultants, doctors, lawyers, sport trainers, and a lot more (Tosey, Mathison \& Michelli, 2005; Kudliskis \& Burden, 2009; Karunaratne, 2010).

Richards and Rodgers (2001) also have introduced NLP as a supplementary technique in teaching second language and Millroad (2004) defined this technique as "An approach to language teaching which is claimed to help achieve excellence in learner performance" (p. 28), enjoying much potential for teaching and learning second language.

A review of the literature on NLP demonstrates that its role in the realm of education and particularly Second or Foreign Language Learning (ESL/EFL) has not been examined effectively. Due to the scarcity of research in this area, we aimed to conduct an investigation into the nature of NLP. To this end, the current study has tried to construct a questionnaire of NLP and subsequently validate it through its application to non-native English teachers and to verify its role in English language teachers' success at high schools in Iran.

\section{THEORETICAL BACKGROUND}

In the following, we will present different models of NLP along with some theoretical and related empirical findings on the concept of teacher success. Since, to our best knowledge, no other research was found to determine the effect of NLP techniques on teachers' success in the classroom we are going to focus on the literature of each variable individually. 
As stated above, trying to reach excellence is the main aspect of NLP. To this end, change is substantial. O' Connor (2001) suggests that change, is a journey from an unsatisfactory present state towards a desired state - your outcome (p. 11). Since all the changes, in the first place, occur at the unconscious level, the unconscious mind is benevolent. One way of changing is offered in TOTE model (Test_ Operation _ Test _ Exit). This model highlights the role of feedback and feed forward in achieving one's goals ( $\mathrm{O}^{\prime}$ Connor, 2001). For any successful change rapport is needed, that is effective relationships must be constructed for the fact that we try to understand the other person from his point of view (O' Connor, 2001). NLP believes that people act according to the way they perceive the world not according to the way the world really is (Tosey, Mathison \& Michelli, 2005). That is, we create our maps of reality individually and do not behave to this world directly (Bandler \& Grinder, 1975). The principal notion of Preferred Representational System (PRS) suggests that individuals construct internal maps of the world by processing external information through five sensory systems: visual, auditory, kinesthetic, olfactory and gustatory (Davies, 2009, p. 59). According to Grinder and Bandler (1976), O' Connor (2001) and Gumm, Walker and Day (1982) PRS manifests itself through "accessing cues" such as body language, eye movement, and voice tone. NLP takes language literally. Predicate phrases and metaphors lead us to the representational system that an individual is using and also the submodalities involved (O' Connor, 2001). O' Connor (2001) states that the senses are the 'modalities' we use to think, so the qualities of the sense experience are 'submodalities' (p. 94). Therefore, changing submodalities changes the meaning of an experience. The core model of NLP, Meta Model, is believed to reflect underlying cognitive processes based on language patterns (Tosey \& Mathison, 2003). Due to its prominent role in eliciting individual's distinct realities, Meta Model is considered as a primary NLP tool (Einspruch \& Forman, 1985). In some ways, the Milton Model is the mirror image of the Meta Model. In contrast to Meta Model that moves from deep structure to surface structure, the Milton Model shifts from surface structure to deep structure. Furthermore, the Meta Model accesses conscious understanding in contrast to the Milton Model that accesses unconscious resources (O' Connor, 2001).

As mentioned earlier, NLP models revealed to be applicable to the realm of education. Since NLP is subjective and constructivist in nature (Craft, 2001); its techniques have been presented quite distinctively by various psychologists and scholars. Nevertheless, the researchers preferred to give the following taxonomy offered by Millroad (2004) as it centered around teaching a second or foreign language to learners: Establishing a rapport between teacher and learners, Modeling the learner, Creating a learner filter, Pacing with the learner, Leading the learner, Elicitation with the learner, Calibration of the learner, Reframing the approach, Collapsing an anchor (p. 30). As he asserted, establishing a rapport was constructed upon teachers' support, empathy and interaction with the learners. For the concept of modeling he suggested providing students with strategies to gain better results. Creating a learner filter required the teacher to verify pupils' responses along with their attitude and knowledge. Pacing was another NLP technique employed to harmonize teachers' and learners' rate, style and production. For the purpose of leading the learners, Millroad (2004) proposed raising cognitive challenges for them; thereafter, pupils had to be directed toward an output that was regarded to as elicitation. Calibration was the process of distinguishing individual differences. Since learners were different from each other, they owned different learning strategies as well. When some strategies were unproductive, reframing would be conducted, i.e. those techniques had to be replaced with other alternatives. Last of all was collapsing an anchor that highlighted supporting students' success and achievements (Millroad, 2004).

\section{B. Teacher Success}

The concept of teacher success has been the major concern of educators and researchers for a long time. Many attempts have been made in the past to specify various factors contributing to teaching effectiveness. A number of features like working condition and the environment (Johnson \& Birkeland, 2003; Korthagen, 2004), teachers' personality along with some of their behavioral aspects (Bhardwaj, 2009; Medley \& Mitzel, 1955) and teachers' ability and skill (Porter \& Brophy, 1988) were investigated to have a great influence on this specific issue.

Evidently, this notion is highly considerable to teacher educators and supervisors due to its direct impact on learning and teaching. For this very reason, in 2007 Elizabeth, May and Chee tried to build a model of teacher success in Hong Kong. They concluded that effective teachers were creative, skilful, and fair in assessment and grading. Additionally, they were managed to engage learners, improve critical thinking and provide feedback. In another attempt to define teachers' success Tamblyn (2000) distinguished seven attributes of successful teachers: Creativity, skill, flexibility, warmth and humor were a few of them. Similarly, in 1967, Beck determined that pupils perceive the effective teacher as a warm, friendly and supportive person. Dodge (1943) concluded that more successful teachers were more sociable, sensitive to people's opinions, responsible, less worried and slower in decision making than less successful teachers. In another survey, Gage (1963) discovered that students' ideal teachers were mostly the ones who would behave as students wanted them to behave.

Along with personal qualities of teachers like patience, enthusiasm and sense of humor, professional qualities are also substantial (Elizabeth, May \& Chee, 2007). For instance Porter and Brophy (1988) identified that another factor leading to teachers' success was the ability and skill of the teacher in employing instructional materials, planning, questioning, assessing and evaluating.

In comparison with other findings that had put so much emphasis on teachers themselves to discover characteristics of successful teachers, Korthagen (2004) and Johnson and Birkeland (2003) found the element of environment, like school facilities, heavy teaching loads and unsupportive administrators, highly interfering. Moafian and Pishghadam (2009) also 
have designed a questionnaire to measure teacher success in schools and language institutes. They have specified 12 constructs which can measure teacher success. It seems that none of the research projects done in teacher education have paid attention to the role of NLP in teacher success.

\section{PURPOSE OF THE STUDY}

Due to the importance of NLP in language teaching, this study intends, first to construct and validate a questionnaire of NLP, and then to apply it as an example to the teaching language in Iran. In fact, this study has two phases: Validation and Application. We hope our instrument can deepen and enrich our understanding of NLP constructs and help researchers conduct more empirical research into the nature of NLP and different issues in language learning and teaching. With that in mind, this study investigates two research questions:

1. What factors are measured by NLP when examined with EFL teachers?

2. Is there any significant relationship between NLP and language teaching success?

\section{METHOD}

\section{A. Participants}

The whole study consisted of two phases: 1) Validation and 2) Application of NLP questionnaire. In the first phase of the study, the sample consisted of 175 EFL teachers who were teaching in high schools $(\mathrm{N}=93)$ and language institutes $(\mathrm{N}=83)$ in Mashhad, Iran. In the second phase of the study, the sample comprised 93 EFL high school teachers along with 1200 EFL students.

During the first phase, participants consisted of 175 EFL teachers aged between 18 and 48 years old $($ Mean $=39)$ with a range of between 1 and 22 years of teaching experience (Mean =13.3). They were 101 females and 73 males from different fields of study; however, the majority of them had majored in the various branches of English like English teaching, English literature, and English translation. Some, nevertheless, had degrees in majors other than English.

Throughout the second phase, the participants comprised 93 EFL teachers (32 males and 61 females) and 1200 EFL students of the mentioned teachers (441 males and 759 females). Students were all at high school level and ranged from 15 to 18 years old (Mean $=16.3$ ). Teachers aged between 32 to 51 (Mean =37) with range of between 6 to 21 years of teaching experience. Their fields of studies were English teaching, English literature, and English translation.

\section{B. Instrument}

In the first place, a questionnaire was constructed and then validated to be used as an instrument for conducting the second phase of this study and also further research in the field of foreign language learning.

The second questionnaire employed for the second phase of the study, to investigate teachers' success in the classroom, was 'Characteristics of successful EFL teachers' (Moafian \& Pishghadam, 2009). This questionnaire consists of 47 multiple choice items varying from "strongly agree" to "strongly disagree". The total reliability of the questionnaire is 0.94 and the results of factor analysis has revealed 12 constructs: teaching accountability, interpersonal relationships, attention to all, examination, commitment, learning boosters, creating a sense of competence, teaching boosters, physical and emotional acceptance, empathy, class attendance, and dynamism.

\section{Data Collection}

Following the taxonomy and guidelines proposed by Millroad (2004), the researchers constructed the related questionnaire adopting a straightforward procedure including three steps: 1) Designing the test 2) Validation 3) Administering the test along with 'Characteristics of successful EFL teachers' questionnaire to investigate their correlation.

Applying the guidelines provided by the experts in the field of psychology and language teaching, the researchers designed the questionnaire with 38 items in the 5 scale Likert type. In doing so, they held joint consultations to revise the items. Then a pilot study was carried out. The questionnaire was administered to 175 EFL teachers of several schools and private language institutes in Mashhad, Khaaf and Torbat, cities in north-eastern of Iran.

Consequently, throughout the third step, the questionnaire was administered to 93 teachers of different high schools. Simultaneously, 'Characteristics of successful EFL teachers' questionnaire was given to 1200 students of the mentioned teachers during class hours by prior arrangement with the administrators.

\section{Data Analysis}

The internal consistency of the whole questionnaire was assessed with the Cronbach Alpha reliability estimate. Moreover, using Cronbach Alpha, the internal consistency of each factor constructing the validated questionnaire was also examined.

The validity of the hypothesized factor structure of the NLP questionnaire was examined through Exploratory Factor Analysis (EFA). Initially, principal axis factoring identified the underlying factors by calculating the eigenvalues of the matrix greater than 1.0. Due to the subjectivity of the criterion for selecting absolute value, the researchers decided to interpret only factor loading with an absolute value 0.30 or greater. To decide about the number of factors to retain for 
rotation, the Scree test was used. Since interpretation of the factors can be very difficult, a solution for this difficulty is factor rotation. In so doing, Varimax (orthogonal rotation) with Kaiser Criterion was used. This resulted in a rotated component matrix and a transformation matrix. The rotated component matrix illustrated the variables loaded on each factor so that the researchers came up with new factors.

Then, the validated questionnaire was applied to identify the NLP factors that the EFL teachers carried out in the classroom. Finally, Pearson product-moment correlation was employed to examine the relationship between the newlymade questionnaire and teacher success. The data was entered into and processed with SPSS 16 program.

Regarding the questionnaire, it comprises 38 items. The items are scored according to the Likert- type scale of five points ranging from (1) "strongly disagree" to (5) "strongly agree". It must be mentioned that scoring scheme of items $24,32,33,34,36,37$ and 38 is vice versa as they are negative statements. That is (5) "strongly disagree" to (1) "strongly agree".

\section{RESULTS}

\section{A. Reliability of the NLP Questionnaire}

The researchers by means of Cronbach Alpha, estimated the reliability of the whole items as 0.82 . After inspecting the factor rotation, none of the items was omitted.

TABLE 1

RELIABILITY OF EACH FACTOR OF THE QUESTIONNAIRE

\begin{tabular}{lcc}
\hline Factors & Cronbach's Alpha & N of Items \\
\hline Factor 1 & .85 & 6 \\
Factor 2 & .74 & 4 \\
Factor 3 & .71 & 5 \\
Factor 4 & .78 & 3 \\
Factor 5 & .81 & 7 \\
Factor 6 & .79 & 4 \\
Factor 7 & .77 & 4 \\
Factor 8 & .82 & 5 \\
\hline
\end{tabular}

\section{B. Construct Validity}

The researchers measured the factorability of the inter correlation matrix by two tests: these tests are Kaiser-MeyerOlkin test of Sampling Adequacy (KMO) and Bartlett's Test of Sphericity. The results of these tests showed that the factor model was appropriate. The results are given in Table 2.

TABLE 2

KMO AND BARTLETT'S TEST

\begin{tabular}{lll}
\hline \multicolumn{4}{c}{ KMO AND BARTLETT'S TEST } \\
\hline \multicolumn{3}{c}{ KMO and Bartlett's Test } \\
\hline \multicolumn{2}{c}{ Kaiser-Meyer-Olkin Measure of Sampling Adequacy } & .704 \\
Bartlett's Test of Approx. Chi-Square & $1.969 \mathrm{E} 3$ \\
Sphericity & df & 703 \\
& Sig. & .000 \\
\hline
\end{tabular}

Then the construct validity of NLP Questionnaire was examined through Exploratory Factor Analysis (EFA). PCA extracted 8 factors with eigenvalues greater than 1 which accounted for $64 \%$ of the variance.

Using the results obtained from the Scree Test, it can be indicated that an eight-factor solution might provide a more suitable grouping of the items in the questionnaire (Figure 1). 


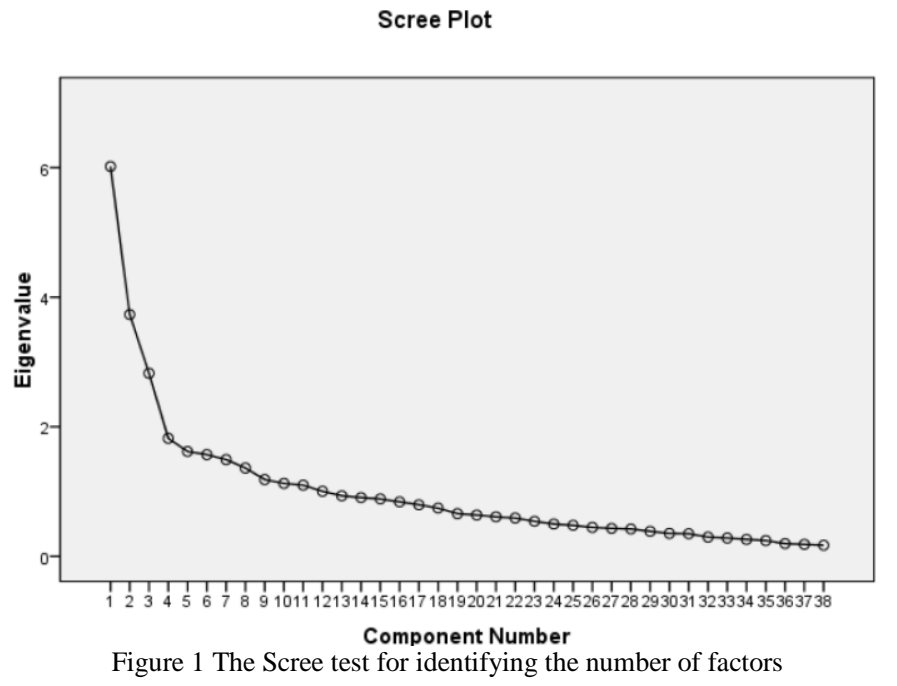

The researchers, then, inspected orthogonal rotation. The result was a rotated component matrix. The results indicated that the first factor consisted of 6 items. The second factor consisted of 4 items. Factor 3 consisted of 5 items. Factor 4 consisted of 3 items. Factor 5 consisted 7 items. Factor 6 consisted 4 items. Factor 7 consisted 4 items, and factor 8 consisted 5 items. The total number of items was 38 . The result of this analysis is shown in Table 3.

TABLE 3

ROTATED COMPONENTS OBTAINED VIA PRINCIPAL COMPONENT ANALYSIS AND THEIR LOADINGS

\begin{tabular}{cccccccc}
\hline Component & Component & Component & Component & Component & Component & Component & Component \\
1 & 2 & 3 & 4 & 5 & 6 & 7 & 8 \\
\hline $36=0.79$ & $35=0.68$ & $28=0.74$ & $30=0.72$ & $21=0.70$ & $7=0.66$ & $2=0.80$ & $19=0.71$ \\
$34=0.74$ & $31=0.57$ & $9=0.68$ & $14=0.68$ & $4=0.70$ & $16=0.59$ & $1=0.71$ & $17=0.58$ \\
$37=0.64$ & $15=0.52$ & $13=0.48$ & $26=0.58$ & $8=0.61$ & $29=0.50$ & $3=0.39$ & $10=0.40$ \\
$33=0.62$ & $25=0.51$ & $18=0.41$ & & $11=0.39$ & $23=0.34$ & $6=0.38$ & $20=0.37$ \\
$24=0.61$ & $32=0.31$ & $12=0.37$ & & & \\
$38=0.52$ & & & \\
7
\end{tabular}

Finally, the researchers analyzed the factors and their comprising items and then named the eight factors as Flexibility, Anchoring, Elicitation, Modeling, Individual differences, Leading, Establishing Rapport, and Emotional and Cognitive Boosters. All the eight factors along with their items are displayed in Table 4. The validated questionnaire is given in Appendix A.

TABLE 4

EIGHT FACTORS OF THE QUESTIONNAIRE

\begin{tabular}{llcc}
\hline \#areas & Statements & N of items & Percentage \\
\hline 1. Flexibility & $36,34,37,33,24,38$ & 6 & 16 \\
2. Anchoring & $35,31,15,25$ & 4 & 10.5 \\
3. Elicitation & $28,9,13,18,32$ & 5 & 13 \\
4. Modeling & $30,14,26$ & 3 & 8 \\
$\begin{array}{l}\text { 5. Individual } \\
\text { Differences }\end{array}$ & $21,4,8,11,12,24,5$ & & 18.5 \\
$\begin{array}{l}\text { 6. Leading } \\
\text { 7. Establishing }\end{array}$ & $7,16,29,23$ & 4 & 10.5 \\
Rapport & $2,1,3,6$ & 4 & 10.5 \\
8. Emotional and & $19,17,10,20,22$ & 5 & 100 \\
Cognitive Boosters & Total & 38 &
\end{tabular}




\section{NLP and Teacher Success}

To determine the association between NLP and teacher success, Pearson product-moment correlation was employed. As Table 5 exhibits there is a significant relationship $(r=0.34, \mathrm{p}<.05)$ between NLP and teacher success. It implies that those teachers who employ more NLP techniques in their classes are more successful than other teachers.

TABLE5

CORRELATION BETWEEN NLP AND TEACHER SUCCESS

\begin{tabular}{|l|c|c|l|}
\hline Variables & $\mathrm{N}$ & Cor. & Sig. \\
\hline NLP & 93 & .342 & $.00 *$ \\
\hline Teacher Success & 93 & .00 \\
\hline
\end{tabular}

*. Correlation is significant at the 0.05 level (2-tailed).

\section{DISCUSSION}

\section{A. The Validated Questionnaire}

This study tried to find out the reliability and validity of the NLP Questionnaire in the context of EFL teachers. The results of this analysis were used to name each factor. In the following the process and the reasons for selecting these names for the eight factors are explained.

1. Flexibility

Flexibility is the label for the first factor which consists of 6 items. As it is shown in the Appendix, items 24, 33, 34, 36, 37 and 38 measure teachers' level of flexibility in classroom context in general. All these items test the negative actions and reactions of the teacher and if the teacher could manage the teaching process in a flexible way or not.

\section{Anchoring}

The second factor is called Anchoring which refers to the process by which an internal or external stimulus triggers a response (Millrood, 2004). This factor consists of 4 items. Items 15, 25, 31 and 35 measure the amount of anchor that occur naturally or is set up intentionally by the teacher. Anchoring is related to students' success and progress, which are involved in items 31 and 35. The learners' need to be involved in class activities is measured by item 25 .

\section{Elicitation}

Factor 3 which is known as Elicitation comprises 5 items. By definition elicitation is refers to evoking a state by one's behavior (Millrood, 2004). Items 9, 13, 18, 28, and 32, test the teacher's strategy in gathering information by direct observation of non-verbal signals or by asking Meta Model questions.

\section{Modeling}

Modeling is the label selected by the researchers for the fourth factor of the questionnaire which includes 3 items. Items 14, 26, and 30 ask to what extent the teacher is successful in the process of presenting the new or difficult material in order to enable the students to accomplish a task. Also these items are related to accelerating learning by the teacher.

\section{Individual Differences}

The fifth factor of the questionnaire is referred to as Individual Differences which is explained as a tendency on the part of the teacher to give every individual student in the classroom a sense of belonging by considering all of their points of view and ideas. Items $4,5,8,11,12,21$, and 27 test the process of engaging all the students equally by the teacher.

\section{Leading}

The sixth factor of the questionnaire that is consisted of 4 items is named Leading, which is referred to as changing one's behavior with enough relationship to motivate the other person to follow you. Items 7, 16, 23, and 29 ask the teacher's skill in leading and helping the students over the learning bridge.

\section{Establishing a Rapport}

Rapport is the label for the seventh factor in this questionnaire. It consists 4 items which are related to the process of establishing and maintaining a mutual relationship full of trust and understanding between the teacher and the learners. Items 1, 2, 3, and 6, test the teacher's ability in making negotiation with learners and generating responses from them.

\section{Emotional and Cognitive Boosters}

The last and eighth factor which is labeled in this questionnaire is Emotional and Cognitive Boosters. It includes 5 factors. Items 10, 17 and 22 test the teacher's ability in bringing an emotional environment to evoke the learners' engagement. Items 19 and 20 are related to teacher's strategies in stimulating and empowering learners' cognition.

\section{B. Teacher Success}

The results of correlational analysis also confirm the association between NLP and teacher success. These results are compatible with the claims of Richards and Rodgers (2001) who espouse the use of NLP techniques in class. Since language teaching is based on communication and interaction, fostering a close rapport is of fundamental importance in class. Besides, the NLP techniques help teachers to be more flexible and caring toward their work and individual learners. By using NLP strategies students will be given greater opportunities to learn effectively. Therefore, it is no wonder that there is association between NLP and teacher success in class. 


\section{CONCLUSION}

The value of this questionnaire lies in constructing an NLP scale which can be of great help to researchers interested in studying NLP. We have utilized exploratory factor analysis as an efficient tool for determining the underlying factors of the instrument. The results have revealed that eight factors represent the underlying structure of the NLP instrument. It is our hope that future research will lead to further evaluation and improvement of this instrument. Researchers should continue to carry out thorough assessment of the psychometric properties of the instrument designed to measure NLP. Only after the true factor structure of the NLP instrument has been examined, can researchers confidently assert conclusions about the role of NLP in language learning and teaching.

The findings of the study also give support to the use of NLP factors in education. In this perspective, NLP is not only used and viewed in terms of counseling (counselor - client relationship) or medical context; rather it is used in terms of education, especially teaching English. As a matter of fact, NLP is a tool that makes learning a psychological process. By using NLP techniques and realizing their role in bringing change in learning and teaching context, the teachers can make progress in achieving their ultimate capabilities. By producing change based on NLP factors, teachers can bring about practical results for learners and attract them more to the class environment emotionally.

Moreover, by providing training courses in practice, NLP can facilitate exploring successful teachers in facing difficult situations. Therefore, this can be beneficial for schools' or English institutes' managers to select and employ those English teachers who will be more successful in their career by using the NLP questionnaire.

In the end, researchers are recommended to examine objectively the relationship between NLP and other related variables such as: motivation, language learning and teaching strategies, age, or gender. These variables seem to be highly related to the NLP factors. Finding any association between these variables and NLP helps us have a better understanding of the role of these factors in second language learning research.

\section{APPENDICES}

\section{A. The Factors of the NLP Questionnaire}

\section{Factor 1: Flexibility}

1. I expect my students to adjust themselves to my teaching rate.

2. I correct all the language learners' errors.

3. The language learners can form groups freely.

4. I run the class in a formal way.

5. I make use of only one teaching method.

6. I do not make use of encouragement for the language learners' progress.

\section{Factor 2: Anchoring}

1. I ask successful language learners to talk about their personal ways of progress in the classroom.

2. I inform my students of their progress.

3. If needed, I ask the language learners to speak clearly.

4. I assign a special duty for every individual.

\section{Factor 3: Elicitation}

1. I get the language learners' ideas of the topics presented in class.

2. To ensure my students` understanding and to remove the ambiguities, I ask them some questions.

3. I create new challenges for the language learners.

4. I welcome new and creative answers.

5. I give feedback to my students`correct and incorrect answers.

\section{Factor 4: Modeling}

1. I write down the new subject material on the board as a model.

2. When the language learners do not understand a subject matter, I write it down on the board.

3. During the teaching process, I write down the new material on the board.

\section{Factor 5: Individual Differences}

1. I pay attention to individual differences.

2. I help the students with less language ability.

3. I pay attention to the language learners' eye movements.

4. I give enough time to the language learners to write down notes and do class activities.

5. I try to create a positive feeling in my students toward language learning.

6. All students`opinions are important to me.

7. When the language learners do not understand something, I present it in a new way.

\section{Factor 6: Leading}

1. I give the language learners the words needed for a conversation.

2. For holding a dialogue, I present the required grammar.

3. For better learning and understanding, I ask the language learners to take notes.

4. I ask my students of my teaching and speaking rate in the classroom. 


\section{Factor 7: Establishing Rapport}

1. In answering the questions, I give hints to students.

2. I show my interest to the topics presented by my students.

3. During teaching, I use some of the words or phrases used by the language learners.

4. I ask my students to pay attention to similarities and differences of the subjects.

\section{Factor 8: Emotional and Cognitive Boosters}

1. I make use of flash cards, CDs, posters, and other teaching aids.

2. I prefer to call my students by their first name.

3. I let my students move freely in the classroom.

4. I ask my students to pay attention to details in the discussing a topic.

5. I talk about myself and my own experiences in the classroom.

\section{B. Neuro-linguistic Programming Questionnaire (NLPQ)}

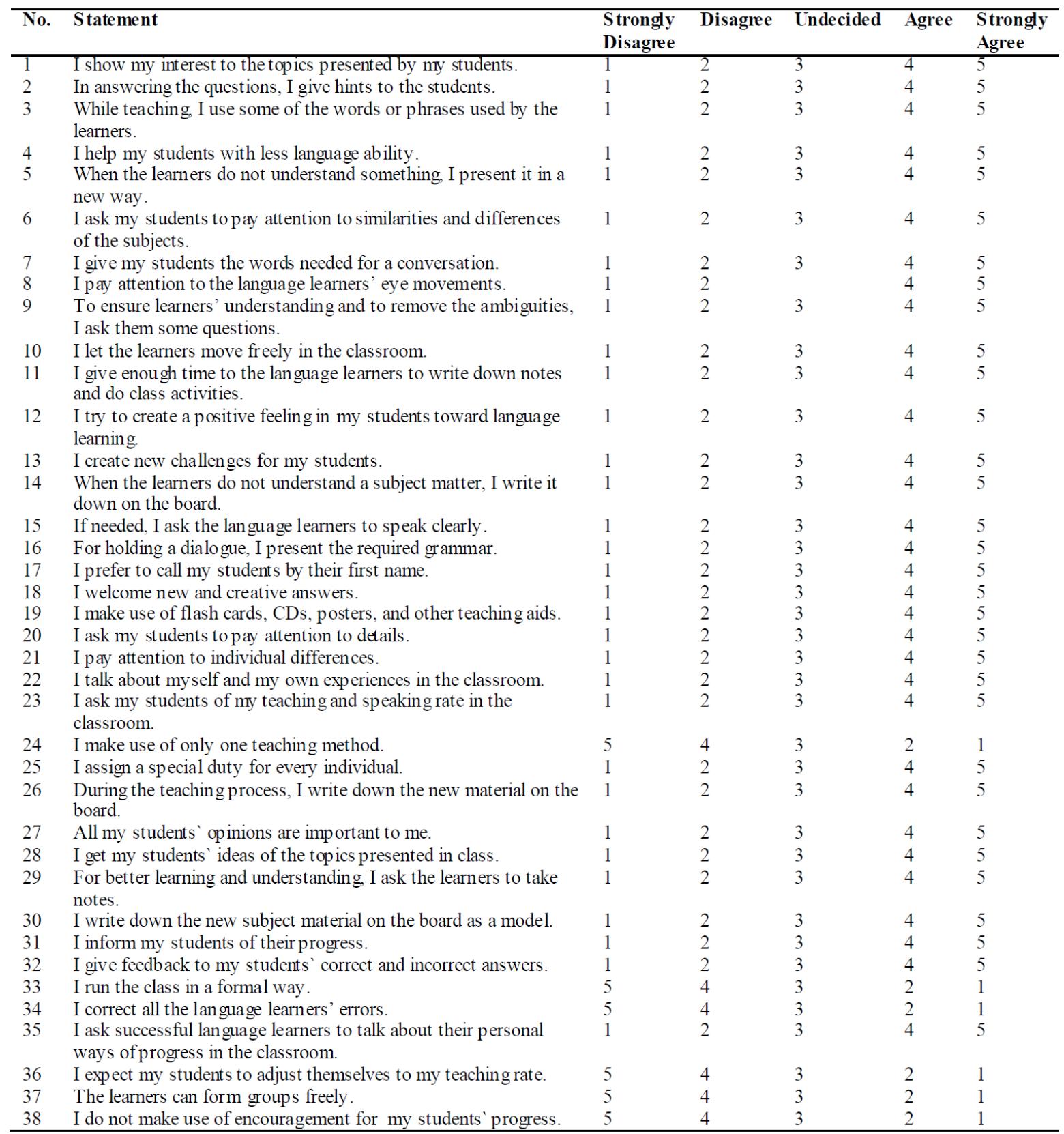

\section{REFERENCES}

[1] Bandler, R., \& Grinder, J. (1975). The structure of magic I. Palo Alto, California: Science and Behavior Books. 
[2] Beck, W. R. (1976). Pupils' perceptions of teacher merit: A factor analysis of five postulated dimensions. The Journal of Educational Research, 61(3), 127-128.

[3] Bhardwaj, A. (2009). Role of personality factors for teaching effectiveness. Pacific Business Review: A Quarterly Journal of Management, 2, 75-80.

[4] Craft, A. (2001). Neuro-linguistic Programming and learning theory. The Curriculum Journal, 12(1), 125-136.

[5] Davies, G. R. (2009). Neuro-Linguistic Programming: A cargo cult psychology? Journal of Applied Research in Higher Education, 1(2), 57-63.

[6] Davies, P., \& Pearse, E. (2000). Success in English Teaching. London: Oxford University Press.

[7] Dodge, A. F. (1943). What are the personality traits of the successful teacher? Journal of Applied Psychology, 27, 325-337.

[8] Einspruch, E. L., \& Forman, B. D. (1985). Observations concerning research literature on Neuro-Linguistic Programming. Journal of Counseling Psychology, 32(4), 589-596.

[9] Elizabeth, C. L., May, C. M., \& Chee, P. K. (2007). Building a model to define the concept of teacher success in Hong Kong. Teaching and Teacher Education, 24, 623-634.

[10] Gage, N. L. (1963). A method for 'improving' teacher behavior. Journal of Teacher Education, 14, 261-266.

[11] Grinder, J., \& Bandler, R. (1976). The structure of magic II. Palo Alto, California: Science and Behavior Books.

[12] Gumm, W.B., Walker, M. K., \& Day, H. D. (1982). Neuro Linguistics Programming: method or myth? Journal of Counseling Psychology, 29 (3), 327-330.

[13] Johnson, S. M., \& Birkeland, S. E. (2003). Pursuing a "Sense of Success": New teachers explain their career decisions. American Educational Research Journal, 40(3), 581-617.

[14] Karunaratne, M. (2010). Neuro-linguistic programming and application in treatment of phobias. Complementary Therapies in Clinical Practice, 16(4), 203-207.

[15] Korthagen, F. A. J. (2004). In search of the essence of a good teacher: towards a more holistic approach in teacher education. Teaching and Teacher Education, 20, 77-97.

[16] Kudliskis, V., \& Burden, R. (2009). Applying 'what works' in psychology to enhancing examination success in schools: The potential contribution of NLP. Thinking Skills and Creativity, 4(3), 170-177.

[17] Medley, D. M., \& Mitzel, H.E. (1955). Some behavioral correlates of teacher effectiveness. Journal of Educational Psychology, 46(6), 330-344.

[18] Millroad, R. (2004). The role of NLP in teachers' classroom discourse. ELT Journal, 58 (1), 28-37.

[19] Moafian, F., \& Pishghadam, R. (2009).Construct validation of a questionnaire on characteristics of successful EFL teachers. Pazhuhesh-e Zabanhe-ye Khareji Journal, 54, 127-142.

[20] O' Connor, J. (2001). NLP workbook. A practical guide book to achieving the results you want (Thorsons ed.). HarperCollins Publishers.

[21] Porter, A., \& Brophy, J. (1988). Synthesis of research on good teaching: Insights from the work of the Institute of Research on Teaching. Educational Leadership, 45(8), 74-85.

[22] Richards, J. C., \& Rodgers, T. S. (2001). Approaches and methods in language teaching. New York: Cambridge University Press.

[23] Sharply, C. F. (1984). Predicate matching in NLP: A review of research on the preferred representational system. Journal of Counseling Psychology, 31(2), 238-248.

[24] Tamblyn, P. (2000). Qualities of success: Lessons from a teacher career. Education Canada, 40(1), 16-19.

[25] Tosey, P., \& Mathison, J. (2003, September). Neuro-linguistic programming: Its potential for learning and teaching in formal education. Paper presented at the European Conference on Educational Research, University of Hamburg.

[26] Tosey, p., Mathison, J., \& Michelli, D. (2005). Mapping transformative learning: the potential of Neuro-Linguistic Programming. Journal of Transformative Education, 3, 140- 167.

Reza Pishghadam is associate professor in TEFL. He is currently in Ferdowsi University of Mashhad, where he teaches Psychology of language education and Sociology of language education. He has published more than 40 articles and books in different journals. His major interests are: Psychology / Sociology of language education, and Language testing.

Shaghayegh Shayesteh is an MA student in TEFL. She studies in Ferdowsi University of Mashhad. Her major interests are: Psycholinguistics and Teaching methodology.

Mitra Shapoori is an MA student in TEFL. She studies in Ferdowsi University of Mashhad. Her major interests are: Psycholinguistics and Teaching methodology. 